\title{
Anabases
}

ANABASES Traditions et réceptions de l'Antiquité

$26 \mid 2017$

Varia

\section{Mary R. BACHVAROVA, From Hittite to Homer. The Anatolian Background of Ancient Greek Epic}

\section{Geneviève Hoffmann}

\section{OpenEdition}

\section{Journals}

Édition électronique

URL : http://journals.openedition.org/anabases/6237

DOI : $10.4000 /$ anabases. 6237

ISSN : 2256-9421

\section{Éditeur}

E.R.A.S.M.E.

\section{Édition imprimée}

Date de publication : 1 novembre 2017

Pagination : 217-220

ISSN : 1774-4296

\section{Référence électronique}

Geneviève Hoffmann, «Mary R. Bachvarova, From Hittite to Homer. The Anatolian Background of Ancient Greek Epic », Anabases [En ligne], 26 | 2017, mis en ligne le 01 novembre 2017, consulté le 20 janvier 2021. URL : http://journals.openedition.org/anabases/6237 ; DOI : https://doi.org/10.4000/anabases. 6237

Ce document a été généré automatiquement le 20 janvier 2021.

(c) Anabases 


\title{
Mary R. BACHVAROVA, From Hittite to Homer. The Anatolian Background of Ancient Greek Epic
}

\author{
Geneviève Hoffmann
}

\section{RÉFÉRENCE}

Mary R. BACHVAROVA, From Hittite to Homer. The Anatolian Background of Ancient Greek Epic, Cambridge, Cambridge University Press, 2016, 649 p.+ XXXVIII, 160.00 dollars / ISBN

978-0-521-50979-4.

1 Spécialiste des cultures de l'Anatolie et du Proche-Orient de l'Âge du Bronze, Mary B. Bachvarova (MBB) présente dans cet ouvrage le fruit de ses recherches sur l'origine anatolienne des épopées homériques. Sa thèse, soigneusement illustrée et solidement documentée, s'ouvre sur une chronologie de l'Âge du Bronze et une table d'équivalence entre les dieux du Proche-Orient et ceux du monde grec. Cet appareil documentaire est complété par deux cartes et le plan de la capitale hittite: Hattusa (la moderne Boğazköy). En fin de volume, la bibliographie détaillée et l'index général sont à l'image d'une ambitieuse démonstration qui embrasse également des questions en marge de l'enquête principale en posant clairement les termes des débats dont elles sont l'objet.

Dans l'introduction (chapitre 1, p. 1-19), MBB situe son propos dans une perspective littéraire et historiographique. Si les parallèles entre l'épopée de Gilgamesh et l'univers homérique sont bien connus, la question reste posée de savoir comment les poètes grecs ont eu connaissance des exploits d'un roi mésopotamien du troisième millénaire. Pour l'auteure, la réponse se trouve dans les tablettes cunéiformes exhumées des bibliothèques d'Hattusa, la capitale des Hittites, textes qui sont en majorité des XIV et $\mathrm{XIII}^{\mathrm{e}}$ siècles. Pour ce qui est de l'historiographie, MBB reconnaît le rôle pionnier joué par Walter Burkert et Martin L. West, mais les pistes qu'ils ont ouvertes dans Orientalizing Revolution, livre publié en allemand en 1984 et traduit en anglais en 1992, n'ont pas été 
aussi fructueuses qu'on pouvait l'espérer pour des raisons idéologiques. Alors que l'influence des Sémites sur les Grecs était acceptée, celle des Hittites était refusée par hostilité à une culture présentée comme «indo-européenne». MBB termine son introduction en présentant avec clarté l'armature de son enquête qui se décompose en quinze chapitres.

3 Figure historique, Gilgamesh qui a régné en Uruk autour de 2600, est le héros dont la geste a été dominante dans la tradition littéraire. Loin de se limiter à son influence sur les épopées homériques, MBB souligne également celle de deux autres récits : «Le Chant de Libération » (chapitres 5, 6 et 7) et «La Légende de Cutha relative au roi Naram-Sin" (chapitre8). "Le Chant de libération", retrouvé en 1983 à l'état fragmentaire à Hattusa, est un écrit bilingue (hourri-hitiite) daté de 1400, qui raconte la sujétion du peuple de la cité d'Ikinkalis par la cité d'Ebla (p.111-113). Le souverain d'Ebla est prié par le dieu Teshshub de relâcher les vaincus, autrement Ebla sera détruite, mais il se heurte à un refus de la part de l'assemblée. L'auteure voit dans la scène d'ouverture du poème homérique la chute programmée de Troie dans la mesure où la ville est détruite parce que les Troyens ont refusé de rendre Hélène aux Achéens. Quant à la malédiction lancée par le dieu Teshshub, elle a son parallèle avec le début de l'Iliade

: Agamemnon provoque la colère d'Apollon qui envoie la peste sur les Achéens parce qu'il refuse de rendre Chryséis. Comme dans " le Chant de Libération ", une assemblée discute du sort de Chryséis (p. 139-142).

L'auteure souligne donc l'importance du thème des captives dans les deux traditions, orientale et grecque.

Quant au roi Naram-Sin, sa démesure en faisait un contre-modèle pour les rois hittites. Dans "La Légende de Cutha ", il a conduit son royaume à la ruine en refusant de se plier aux oracles des dieux qui lui conseillaient de ne pas sortir de la ville d'Akkad. Il ne fut sauvé que par l'intervention d'Ishtar dont il finit par suivre les avis. La morale de l'histoire est que le roi est responsable du succès ou de la destruction de son peuple. Les scribes entendaient bien faire valoir ce message auprès des puissants (p. 192-193). Pour l'auteure, il est possible d'établir un parallèle entre Naram-Sin et Hector, véritable héros de l'Iliade. Comme lui, il ne tient pas ses troupes à l'intérieur des murs de Troie et se refuse à écouter Polydamas qui sait interpréter le présage envoyé par Zeus (Iliade, XII, v. 200-250) (p. 193-195).

5 MBB fait des poètes les agents principaux de la transmission orale de cette tradition épique, transcrite par les scribes en sept langues différentes. Elle accorde une grande place aux fêtes religieuses comme moments de transferts culturels qui transcendent les frontières linguistiques et géographiques. Les Grecs reconnaissaient d'ailleurs qu'ils avaient hérité de leurs fêtes et de leurs dieux. L'auteure donne plusieurs exemples de ces héritages. L'Apollon de Didyme est dans la continuité d'Apallu Arzawan (p. 248). Semblablement, les mythes relatifs à Aphrodite amalgament des traits helladiques, indo-européens et proche-orientaux. Pour MBB, la déesse de l'Hymne homérique à Aphrodite prouve l'importance de Chypre dans l'interaction entre les hellénophones et les poètes porteurs de la tradition orientale. La Cilicie joua également un rôle dans ces transferts culturels anatoliens vers l'ouest après la chute du royaume hittite.

6 La thèse de $\mathrm{MBB}$ ne se limite pas à ce fonds littéraire. Elle met également en lumière les convergences entre les sociétés grecques et anatoliennes de l'Âge du Bronze. Des exemples tirés de l'Odyssée 
témoignent de ces élites soucieuses de connaître les histoires sur l'origine du monde et les récits relatifs aux voyages lointains pour élargir leur horizon et gagner en prestige. Elle souligne que les élites grecques et anatoliennes avaient le même besoin de légitimité et partageaient les mêmes valeurs

: hospitalité et émulation, en particulier dans les courses de chars. De toutes les routes du commerce la plus importante est celle qui partait du nord de la Syrie et de la Cilicie, en passant par Chypre, pour atteindre l'Eubée. Les influences orientales sont attestées avant 825 , date des tombes associées à l' herôon de Lefkandi. C'est en effet dans la période des âges dits " obscurs ", que les Grecs ont commencé à élaborer à propos des héros une mémoire collective, fondée sur les catégories narratives proche-orientales.

7 En philologue et en historienne, MBB cherche l'origine et la signification de la guerre de Troie. Pour comprendre ses enjeux, elle insère ce conflit entre Achéens et Hittites dans la géopolitique de l'Anatolie orientale, au second millénaire. Elle défend l'idée que l'histoire de la chute de Troie est au départ une histoire anatolienne, racontée d'un point de vue anatolien avant d'être reprise par les Grecs. Des arguments qu'elle développe, on peut retenir que le fils de Priam est appelé Alexandre par les Grecs et les Troyens quand ils parlent aux Grecs, alors qu'il est appelé Pâris par les Troyens quand ils parlent à d'autres Troyens. Ce double nom serait la réminiscence d'une tradition dynastique de l'Âge du Bronze anatolien selon laquelle porter deux noms signifiait un double héritage. L'auteure explique des épisodes de l'Iliade par l'influence culturelle des peuples anatoliens (tableau 4). Ainsi, la prééminence des Lyciens dans l'Iliade avec le héros Sarpédon s'expliquerait par le rôle de Milet dans le développement et le transfert des mythes lyciens aux Ioniens.

8 En marge de sa démonstration, MBB développe plusieurs aspects particuliers comme la katabasis du chant XI de l'Odyssée. Cet épisode homérique témoigne à maints égards d'une influence orientale. Ulysse fait venir les morts à lui grâce à un rituel anatolien qui ne relève pas de la nécromancie. En effet, le héros ne reçoit des informations sur son avenir que du devin Tirésias. Pour l'auteure, ses échanges avec les morts évoquent le catalogue des héros développé dans le récit de la visite dans l'autre monde d'Endiku, le meilleur ami de Gilgamesh.

D'après cette thèse, les épopées homériques ne trouveraient donc pas leur origine dans la culture mycénienne, mais dans les récits épiques et mythologiques, hittites et proche-orientaux. Formalisées entre 1160 et 1050, elles seraient contemporaines de la naissance de la légende de la guerre de Troie. Par ce travail monumental, dont cette critique n'épuise pas la richesse, Mary B. Bachvarova offre aux spécialistes une riche documentation pour comprendre et discuter les interactions culturelles entre des sociétés souvent présentées comme éloignées les unes des autres, dans une période comprise entre 1175 et 700 avant notre ère.

$10 \mathrm{Si}$, de chapitre en chapitre, le thème de l'oralité est omniprésent, c'est que l'auteure entend rompre avec l'image traditionnelle d'une culture orientale écrite qui fait de la transcription des mythes et des légendes un exercice d'école, réservé à la formation des scribes. D'après cette démonstration, les épopées mésopotamiennes, loin d'être limitées à un milieu fermé, ont été chantées et donc largement diffusées, y compris dans les sociétés hellénophones. 


\section{AUTEURS}

\section{GENEVIĖVE HOFFMANN}

Université de Picardie Jules Verne

genevieve.hoffmann@wanadoo.fr 